\title{
R5 - Kit NAT HIV/HCV/HBV Bio-Manguinhos - Eficácia para detecção do alvo HBV em amostras em período de janela imu- nológica
}

Patricia Alvarez ${ }^{1 *}$; Elisabete Andrade ${ }^{1}$; Daniele Rocha ${ }^{1}$; Marcela Fontana ${ }^{1}$; Elaine Costa $^{1}$; Marisa Ribeiro ${ }^{1}$; Antonio G.P. Ferreira ${ }^{1}$.

\section{1 - Bio-Manguinhos/FIOCRUZ}

\section{Introdução:}

O ensaio NAT Brasileiro para triagem de doadores visa complementar a rotina de ensaios sorológicos, diminuindo o período de janela de imunológica, ou seja, período onde os testes sorológicos não são capazes de detectar a resposta imune para estes vírus em doadores de sangue, levando então a diminuição do risco residual transfusional para estes patógenos.

\section{Objetivo:}

Ampliar ainda mais a segurança transfusional no Brasil, através da implantação da nova versão do Kit NAT Brasileiro, produzido por Bio-Manguinhos, que incorpora o novo alvo HBV, adicionalmente. A detecção do alvo HBV em amostras no período de janela imunológica confirma a aplicabilidade e eficácia do produto.

\section{Metodologia:}

Em curtíssimo espaço de tempo foram superados os desafios científicos, técnicos e operacionais para incorporar o novo alvo HBV ao produto, para o qual se obteve a alteração do registro junto a ANVISA, em novembro de 2014. O novo modelo de produto foi incorporado gradualmente às rotinas dos Serviços de Hemoterapia, para triagem de doadores de sangue. O Kit NAT HIV/HCV/ HBV brasileiro é um ensaio baseado na técnica de PCR em tempo real, contemplando um ensaio triplex discriminatório (HIV, HCV e PC) e um duplex discriminatório (HBV e PC) com alto grau de automação, alta capacidade de processamento e sensibilidade.

\section{Resultados:}

Segundo a Coordenação Geral de Sangue e Hemoderivados/MS, desde dezembro de 2014, foram processadas com o Módulo de amplificação de HBV do Kit NAT Brasileiro, cerca de 400 mil amostras de doadores de sangue. Até o 
momento, foram notificadas 3 amostras HBV detectáveis no Kit NAT e não reagentes na sorologia, caracterizando o período de janela imunológica. Destas, 2 foram detectadas no Hemocentro de Minas Gerais e 1 no Hemocentro de Pernambuco. Além destas amostras, o produto foi capaz de obter excelente desempenho frente a painéis de soro-conversão para HBV. Nos ensaios de LOD utilizando os painéis NIBSC, o Kit foi capaz de detectar replicatas com até 3UI/ $\mathrm{mL}$. Estes dados vêm comprovando a aplicabilidade e desempenho esperado para o Kit NAT HIV/HCV/HBV Bio-Manguinhos.

\section{Conclusão:}

O Kit NAT HIV/HCV/HBV Bio-Manguinhos e sua aplicação nas rotinas de triagem de doadores de sangue no Brasil geraram aumento na segurança transfusional sem significativos impactos operacionais e de custo, constituindo um exemplo de produto inovador para o Complexo Industrial da Saúde. Contribui ainda para consolidar competências tecnológicas na área de imunobiológicos e diagnóstico molecular na FIOCRUZ, atendendo à demanda de produtos estratégicos do Ministério da Saúde para o SUS.

Palavras-Chave: Diagnóstico molecular, Kit NAT, Detecção de Janela Imunológica 